\title{
Cutaneous lumbosacral injections of sterile water were more effective than "placebo" injections for relieving first stage labour pain
}

Mårtensson L, Wallin G. Labour pain treated with cutaneous injections of sterile water: a randomised controlled trial. Br J Obstet Gynaecol 1999 Jul;106:633-7.

QUESTION: In women who are in the first stage of labour, are cutaneous injections of sterile water effective for relieving low back pain?

\section{Design}

Randomised (allocation concealed*), blinded (outcome assessors,)* placebo controlled trial with 90 minute follow up after treatment.

Setting

A labour ward with approximately 3000 deliveries/year in a suburb of Gothenburg, Sweden.

\section{Patients}

99 pregnant women (mean age $29 \mathrm{y}$, mean gestation $40 \mathrm{wk}$ ) who were admitted to the labour ward, were in the first stage of labour, required pain relief for severe low back pain, and had not received either opioid analgesia in the previous 3 hours or an epidural blockade. $98 \%$ and $87 \%$ of women were studied at 10 and 45 minutes, respectively, after treatment.

\section{Intervention}

Women were allocated to 4 intracutaneous injections of $0.1 \mathrm{ml}$ sterile water $(\mathrm{n}=33), 4$ subcutaneous injections of $0.5 \mathrm{ml}$ sterile water $(\mathrm{n}=33)$, or 4 subcutaneous injections of $0.1 \mathrm{ml}$ isotonic saline (placebo). Injections were given in the lumbosacral region (Michaelis rhomboid) during a contraction while the woman breathed nitrous oxide and oxygen.

Source of funding:

Bohus County Health

Authority.

\section{Main outcome measure}

Labour pain was measured with a $10 \mathrm{~cm}$ visual analogue scale (VAS) $(0 \mathrm{~cm}=$ no pain; $10 \mathrm{~cm}=$ worst conceivable pain) at 10,45, and 90 minutes after treatment.

Dr G Wallin,

Department of

Obstetrics and

Gynaecology,

Sahlgrenska University

Hospital, S-416 85

Gothenburg, Sweden.

Fax +4631258374.

\section{Main results}

After treatment, labour pain was reduced more in the 2 treatment groups than in the placebo group at $10 \mathrm{~min}-$ utes (median VAS score decrease $5.0 \mathrm{~cm}$ for intracutaneous sterile water and $4.5 \mathrm{~cm}$ for subcutaneous sterile

Intracutaneous (IC) and subcutaneous $(S C)$ injections of sterile water v placebo for relieving labour pain (VAS score reduction $\geq 4.0 \mathrm{~cm}$ ) $†$

\begin{tabular}{lllll} 
Comparisons & Sterile water & Placebo & RBI (95\% Cl) & NNT (CI) \\
IC $v$ placebo at $10 \mathrm{~min}$ & $63 \%$ & $25 \%$ & $150 \%(35$ to 393$)$ & 3 (2 to 8$)$ \\
\hline SC $v$ placebo at $10 \mathrm{~min}$ & $58 \%$ & $25 \%$ & $130 \%(23$ to 358$)$ & 4 (2 to 12$)$ \\
\hline IC $v$ placebo at $45 \mathrm{~min}$ & $59 \%$ & $25 \%$ & $134 \%(21$ to 387$)$ & 3 (2 to 13$)$ \\
\hline SC $v$ placebo at $45 \mathrm{~min}$ & $52 \%$ & $25 \%$ & $107 \%(4$ to 337$)$ & 4 (3 to 82$)$ \\
\hline
\end{tabular}

†VAS = visual analogue scale. Other abbreviations defined in glossary; RBI, NNT, and Cl calculated from data in article.

water $v 1.7 \mathrm{~cm}$ for placebo $[\mathrm{p}=0.002])$ and 45 minutes (median VAS score decrease $4.9 \mathrm{~cm}$ for intracutaneous sterile water and $4.0 \mathrm{~cm}$ for subcutaneous sterile water $v$ $1.0 \mathrm{~cm}$ for placebo $[\mathrm{p}=0.006])$. At 90 minutes, $<80 \%$ of women were included in the analysis. More women in the treatment groups than in the placebo group had pain score reductions $\geq 4 \mathrm{~cm}$ at 10 minutes $(\mathrm{p}=0.005)$ and 45 minutes $(\mathrm{p}=0.027)$ (table).

\section{Conclusion}

In women who were in the first stage of labour, both intra- and subcutaneous injections of sterile water were effective for relieving first stage back pain for 45 minutes.

*See glossary.

\section{COMMENTARY}

Nearly all women experience pain during labour. The response to pain during childbirth is a complex, personal, perceptual experience, modified by physiological and psychological mechanisms that may arise naturally from an endogenous source or an external stimulus. The randomised, placebo controlled trial by Mårtensson and Wallin showed that giving intracutaneous and subcutaneous injections of sterile water in the lumbosacral region may help reduce low back pain during the first stage of labour.

This intervention can be used in most societies, but the risk for needlestick injuries and spread of viral diseases (eg, HIV and hepatitis B virus) could be increased. Alternative pain relief methods that are effective, inexpensive, and easy to give with few side effects should be available.

Although the study sample is small and the loss of data could have influenced the conclusions, this intervention may provide a temporary pain stabilising effect. Further evidence is needed before concluding that intracutaneous and subcutaneous injections of sterile water substantially reduce low back pain during the first stage of labour. However, because no harmful effects and few side effects (ie, pain during injection and increased risk for transmission of HIV and hepatitis B virus to the caregiver) occur, this intervention could be among the alternatives offered to women for pain relief during labour.

Cheryl Nikodem, DCur, MCur University of the Witwatersrand Johannesburg, South Africa 